\title{
Article \\ Near-Death Experiences and Religious Experience: An Exploration of Spirituality in Medicine
}

\author{
Jonathan Kopel ${ }^{1, *}$ (i) and Mark Webb ${ }^{2}$ \\ 1 Texas Tech University Health Science Center, Lubbock, TX 79430, USA \\ 2 Department of Philosophy, Texas Tech University, Lubbock, TX 79409, USA; mark.webb@ttu.edu \\ * Correspondence: jonathan.kopel@ttuhsc.edu
}

check for updates

Citation: Kopel, Jonathan, and Mark Webb. 2022. Near-Death Experiences and Religious Experience: An Exploration of Spirituality in Medicine. Religions 13: 156. https://doi.org/10.3390/ rel13020156

Academic Editor: Greg Peters

Received: 8 January 2022

Accepted: 9 February 2022

Published: 11 February 2022

Publisher's Note: MDPI stays neutral with regard to jurisdictional claims in published maps and institutional affiliations.

Copyright: () 2022 by the authors. Licensee MDPI, Basel, Switzerland. This article is an open access article distributed under the terms and conditions of the Creative Commons Attribution (CC BY) license (https:// creativecommons.org/licenses/by/ $4.0 /)$.

\begin{abstract}
There has been a continuous discussion of religious experience since William James, culminating in a rich and varied literature on the epistemology of religious experience in the late twentieth century. There has also been a burgeoning literature on near-death experiences (NDEs), largely on neurology and physiology and sometimes as possible counterevidence to naturalism. One important subject is largely missing, and that is a discussion of NDEs as religious experiences, and what light that might shed on their epistemic status. This paper is an attempt to fill that gap. In part one, we will delineate the topic of NDEs and what medical science has to say about them. In part two, we will lay out a general view of the epistemology of religious experience. In part three, we will apply that understanding of religious experience to NDEs and draw what lessons we may.
\end{abstract}

Keywords: near-death experiences (NDE); religious experience; framework; experience

\section{Introduction}

At the heart of religious belief are numerous claims of personal experiences with a divine or unseen reality (Badham 1997). Accounts of religious experiences are reported in all major world religions (e.g., Christianity, Judaism, Islam, and Buddhism) and non-religious traditions from ancient to modern times. Although rational argumentation, revelation, and tradition have been at the foundation of religious belief, religious experiences have been the existential component for solidifying an individual's religious belief and relationship with the divine. Religious experiences are a common occurrence for many believers. A Pew Research Study found that approximately $65 \%$ of Americans surveyed also expressed a belief or reported having experienced some form of supernatural phenomena, such as a belief in reincarnation, belief in spiritual energy, having been in touch with the dead, or experiencing a ghostly encounter (Pew Research Center 2009). Furthermore, 49\% of all Americans reported having some form of "a religious or mystical experience-that is, a moment of religious or spiritual awakening" (Pew Research Center 2009). Among non-religious participants, 30\% described having a religious or mystical experience (Pew Research Center 2009). In 1962, only 22\% of Americans surveyed reported having a mystical or religious experience, which increased to $31 \%$ in 1976 and 33\% in 1994. Since then, the proportion of Americans reporting having a religious or mystical experience has continued to increase (Pew Research Center 2009).

In most instances, mystical or religious experiences are common among those who regularly attend religious services. More than $60 \%$ who attend weekly reported having a religious or mystical experience (Pew Research Center 2009). Among those who attended a religious service monthly or yearly, only $48 \%$ reported a religious or mystical experience (Pew Research Center 2009). Only 33\% of those who seldom or never attended a religious service reported having any religious or mystical experience (Pew Research Center 2009). Based on these results, religious experience of a kind is far more widespread than often supposed. The high prevalence of religious experiences among religious and non-religious 
participants is also surprising given the predominant scientific worldview adopted by much of Western culture and society. Of course, the correlation can be explained in many ways, including that having mystical experiences increases the likelihood of attending religious services, or that both are caused by some third factor (Greyson 2010). It may be that regular attendance at religious services increases the likelihood of having a mystical experience, or it may be that having mystical experiences increases the likelihood of attending religious services.

Along with the increase in reported religious or mystical experiences, there has been an upsurge in reports of near-death experiences (NDEs) (Badham 1997). Similar to religious experiences, NDEs produce profound and life-changing effects that share many characteristics of religious or mystical experiences found in many of the world's religions (Badham 1997; Facco et al. 2015; Greyson 2010, 2015). In general, individuals who have experienced an NDE report a variety of experiences, such as out-of-body experiences, looking down at themselves during their resuscitation, feeling a sense of life-review, meeting deceased relatives and friends, or enjoying a mystical experience with a figure identified in a person's own religious traditions (Badham 1997; Facco et al. 2015; Greyson 2010, 2015). As a result of modern resuscitation techniques, thousands of patients routinely report experiencing NDEs during traumatic injury or emotionally traumatic events. According to a random survey in the United States (US) and Germany, four percent of the total population in the Western world have reported experiencing an NDE (van Lommel 2014). Other clinical studies have estimated the prevalence of NDEs to occur in $10 \%$ to $20 \%$ of patients who have come close to death (Greyson 1998). More recent estimates estimate NDEs occur in 4-9\% of general community members and up to $23 \%$ of critical illness patients (Cant et al. 2012). These experiences share many of the characteristics of the deepest religious experiences known to humanity (Badham 1997; Facco et al. 2015; Greyson 2010, 2015).

The descriptions of NDEs appear routinely across religious traditions, cultures, or worldviews (Badham 1997). As Daniel Van Egmond explained,

"It is highly probable that some types of (religious) experience suggested to man that he is able to exist independently of his physical body. For instance, the so-called near-death experiences, out-of-the-body experiences, and shamanistic trances are easily interpreted this way. Indeed, the occurrence of altered states of consciousness is such a common feature in most cultures that it is very probable that such experiences were interpreted as perceptions of so-called "higher worlds"'". (Egmond 1993)

The similarities and differences in NDEs across cultures highlight comparable and contrasting themes. Local themes appear to be the most important. While being 'dead' and so separated from the body is accepted, the transcendence of the Western European concept is not as evident in many texts describing NDEs in other cultures (Belanti et al. 2008). These NDEs had more practical themes including food offerings, being sent back due to mistakes, and a larger emphasis on good and evil. It was also more frequent to meet departed relatives. Although certain characteristics of NDEs are definitely impacted by culture, others, such as altered states of consciousness and generalized visions, are universal. The substance and significance of NDEs may have changed over time, depending on the extent of religious influence and engagement in society (Belanti et al. 2008). Although cultural variables must be considered when attempting to evaluate individual accounts, there may be a fundamental component to NDE. More research is needed to understand the influence of culture, religion, and society on NDEs. The study of published materials in their original languages, collaboration with multilingual professionals, and broadening the literature search to include religious/spiritual, ethnographic, and anthropological studies could result in a body of materials that can be used to investigate the interplay of cultural meaning systems and neurobiology in NDEs (Belanti et al. 2008).

There has been a continuous discussion of religious experience since William James, culminating in a rich and varied literature on the epistemology of religious experience in the late twentieth century. In many instances, NDEs are an important aspect of scholarly 
discussions often overlooked despite their potential to shed light on the epistemic status of religious or mystical experiences. Therefore, examining NDEs may provide a framework through which to describe religious experiences in a well-defined and accessible manner to help physicians understand the elements of spirituality in themselves and their patients.

\section{Near-Death Experiences}

Although NDEs have been reported throughout history, the first account of NDEs reported in academic circles was by Albert von St. Gallen Heim in 1892 (Noyes and Kletti 1972). In general, NDEs are vivid, subjective experiences that occur during life-threatening emergencies, such as cardiac arrest, head injury, shock after loss of blood, or asphyxiation (Facco et al. 2015). Near-death experiences have also been reported in patients in nonlife-threatening conditions during isolation, depression, or meditation, or without any obvious reason (van Lommel 2014). According to Bruce Greyson, the experiential elements of NDEs are classified into four main categories: cognitive features, including things such as time distortion; affective features, including feelings of love and cosmic unity; paranormal features; and transcendental features such as mystical encounters with spirits and an uncrossable border (Greyson 1983). In out-of-body experiences (OBEs), patients can experience veridical perceptions from a position outside and above their lifeless body (Greyson 2015; van Lommel 2013). A recent clinical report of an intensive care unit patient NDE illustrates the colorful and unique aspects of OBEs. In his interview, the patient described his NDE, stating that,

"It seemed to be four to five seconds! It was unusual; I went up. ... It was so painless; there was no pain ... I was so happy ... I was enjoying myself ... I looked back and I could see my bed, my body in the bed. I could see everything that was happening on the floor. I saw doctors when I was up there; I was looking down and could see the doctors and even the sister, what she was actually doing in the ward. It was marvelous; I could see nurses around me and the doctors". (Sartori et al. 2006)

Similarly, NDE patients can experience consciously returning to their body after their OBEs. In many instances, trauma patients describe feeling "locked up" in their body, experiencing all the pain and restriction of their disease or injury, which they were free from during the NDE (van Lommel 2013). As one patient described,

"And when I regained consciousness in my body, it was so terrible, so terrible ... that experience was so beautiful, I never would have liked to come back, I wanted to stay there ... and still I came back. And from that moment on it was a very difficult experience to live my life again in my body, with all the limitations I felt in that period". (van Lommel 2013)

These dramatic shifts in perspective often have profound influences on a person's understanding of their mortality.

Some NDE patients also experience previews, or flash-forwards, in which future images from personal life events and general experiences from the future come to the individual (van Lommel 2013). In other instances, NDEs may include personal interactions with a patient's deceased acquaintances or relatives. As one patient described,

"During my cardiac arrest I had an extensive experience ( . . ) and later I saw, apart from my deceased grandmother, a man who had looked at me lovingly, but whom I did not know. More than 10 years later, at my mother's deathbed, she confessed to me that I had been born out of an extramarital relationship, my father being a Jewish man who had been deported and killed during the second World War, and my mother showed me his picture. The unknown man that I had seen more than 10 years before during my NDE turned out to be my biological father". (van Lommel 2013)

Such experiences with deceased relatives can have a profound effect on the individual, allowing for both closure and peace with their loved one's passing (van Lommel 2013). 
In other instances, NDE patients can experience a holographic life review and experience a sense of unity, peace, and interconnectedness knowing that their actions are connected and integral to the lives of their loved ones and the entire world. For religious individuals and cultures, this may be interpreted as a cosmic law in which everything one does to others will ultimately be returned to oneself (van Lommel 2013). An NDE patient reflected on their holographic life review, stating,

"All of my life up till the present seemed to be placed before me in a kind of panoramic, three-dimensional review, and each event seemed to be accompanied by a consciousness of good or evil or with an insight into cause or effect. Not only did I perceive everything from my own viewpoint, but I also knew the thoughts of everyone involved in the event, as if I had their thoughts within me. This meant that I perceived not only what I had done or thought, but even in what way it had influenced others, as if I saw things with all-seeing eyes. And so, even your thoughts are apparently not wiped out. And all the time during the review the importance of love was emphasized. Looking back, I cannot say how long this life review and life insight lasted, it may have been long, for every subject came up, but at the same time it seemed just a fraction of a second, because I perceived it all at the same moment. Time and distance seemed not to exist. I was in all places at the same time, and sometimes my attention was drawn to something, and then I would be present there". (van Lommel 2013)

Descriptions of near-death experiences can also be influenced by the culture, religion, or prior beliefs of the individual. For example, Christian and Buddhist cultures are more likely to describe NDEs as a tunnel sensation or life review, which is a rare description among native populations in North America, Australia, and the Pacific islands (Greyson 2015). However, there is a growing consensus that the interpretations of NDEs are largely based on the available images, concepts, and symbols available to the individual regardless of culture or religion. However, NDEs may not always be pleasant or a curious experience for a patient. In some instances, patients have reported NDEs as being particularly terrifying or "hellish" in some reports (Greyson 2015). In this manner, NDEs encompass a wide range of experiences that resemble several aspects of religious experiences.

In recent years, the literature on NDEs and the mind-body relationship has exponentially increased (Fischer and Mitchell-Yellin 2014; Rousseau 2011; Sleutjes et al. 2014; van Lommel 2006). The increased interest is related to the enormous challenge NDEs bring towards the predominate naturalistic paradigm of Western culture and science (Greyson 2015). Specifically, NDEs prove anomalous to present neuroscientific models of the brain and cognitive processes (Greyson 2010). As Bruce Greyson explained,

"In sum, the challenge of NDEs to materialist reductionism lies in asking how complex consciousness, including mentation, sensory perception, and memory, can occur under conditions in which current physiological models of mind deem it impossible. This conflict between a materialist model of brain-mind identity and the occurrence of NDEs under conditions of general anesthesia or cardiac arrest is profound and inescapable. Only when we expand models of mind to accommodate extraordinary experiences such as NDEs will we progress in our understanding of consciousness and its relation to brain". (Greyson 2010)

Beyond impacting our understanding of consciousness, NDEs have life-long impacts on those who experience them.

\section{Spiritual Impact of NDEs}

In many instances, NDEs have a profound impact on individuals as they seek to incorporate the sense of awe and wonder of their experience into their daily life (Khanna and Greyson 2014b). Patients often seek to re-experience and appreciate their experiences with respect to the sacred. During these explorations, patients who experienced NDEs show radical and permanent transformations of their attitudes, beliefs, and lifestyles (Khanna and 
Greyson 2014b). Patients also show an increase in spirituality, empathy, and appreciation of life along with a decrease in the fear of death, material concerns, and competitiveness (Greyson and Khanna 2014). Specifically, many patients who experience NDEs report a stronger belief in life after death, renewed sense of purpose, increased self-esteem, greater compassion and love for others, and a deeper interest in religious faith and spirituality (Greyson and Khanna 2014; Greyson 2015). These results are observed among those who previously identified as atheist or non-religious. Given the significant changes following an NDE, it is possible that NDEs provide a framework towards understanding the impact of religious experiences on an individual's worldview and spiritual life.

\section{Understanding Religious Experience through NDEs}

The characteristic patterns for NDEs include: 1 . feeling peaceful and tranquil; 2. experiencing a sense of detachment from one's physical body; 3 . observing one's surroundings from a position above the self; 4 . entering into a dark region or void; 5 . perceiving a region of brilliant light and unusual beauty; and 6 . occasionally encountering other beings such as God, Jesus, or deceased relatives (McLaughlin and Malony 1984). Since religion tackles fundamental human issues such as death and dying, one could hypothesize that religious inclination is linked to near-death experiences. Therefore, there is a link between religious experience and NDEs. Religious experiences may be described as experiences that seem to be of objective reality and religious importance to the person. This reality might be an individual, a situation, a truth, or even an absence (McLaughlin and Malony 1984).

The experiences depend partly on the religious traditions in which the subject is embedded. However, there are features they all tend to share. Williams James was the first to attempt an analysis of those common features, producing a framework that many have used since (Greyson 2014; James 1902; Pennachio 1986). In his book, William James outlines key distinctions with regards to religious experience. Specifically, James explored the difference between institutional and personal religions. Institutional religion refers to the religious group or institution and has a significant role in the culture of society. Personal religion in which the person has a mystical experience, independent of culture, can be experienced (James 1902). In either situation, James concluded that religious experiences are characterized by four features. These features can be summarized through the mnemonic PINT, which stands for:

- Passive-The individual's experience occurs mainly without conscious control. Although it can make religious experiences more probable, practices such as meditation are not something which can be turned on or off at will.

- Ineffable-The experience cannot be adequately put into words.

- Noetic-The person thinks he or she learns something precious from the encounter. Feels like information has been obtained which is usually concealed from human awareness.

- Transient-It is a brief experience: the person recovers quickly to a "normal" mental state. Feels outside of conventional space and temporal perspective.

In examining religious orientation, many people have favorable opinions on death, such as hoping for an afterlife of rewards, and have a strong religious orientation (McLaughlin and Malony 1984). On the other hand, an externally oriented religious person usually has negative attitudes towards death, such as concerns of solitude or agony, and uncertainty. In general, internal religious (intrinsic) individuals have more positive attitudes towards death and less dread of dying. Those seeking personal advantage or religious support (extrinsic and consensus) showed more unfavorable views of death and a greater fear of death (McLaughlin and Malony 1984).

If intrinsically religious people had a reduced fear of death, then one may infer that they could be more involved in the near-death experience than if the dread of death was a barrier for the full experience of the NDE. It is also possible to be more sensitive to the NDE, which may be regarded as a transition to another level, if you have a vital relationship with God-a spiritual, nonmaterial presence (McLaughlin and Malony 1984). Similar to other 
religious experiences, NDEs are viewed as transitions in awareness from a regular mode of consciousness to a different mode of consciousness. The temporal constraints of human life are overcome in this dimension and the person experiences fresh and unique feelings such as communication with departed relatives or a luminous entity. In contrast, some people experience an NDE before they were ever converted to a specific religion (McLaughlin and Malony 1984). In some cases, these patients reported that the NDE was not an important religious conversion factor. Others considered NDE to be a religious experience that was not comprehensible. As part of their NDE, for example, they witnessed the medical staff operating on them outside of their body but did not experience any divine presence or any religious experiences. It is worth noting that these individuals have not even tried to integrate their experience of near death into their religion (McLaughlin and Malony 1984). In contrast, NDEs have led other people away from their former religious views. These people claimed that the NDE was inconsistent with their earlier religious knowledge so that they changed their religious beliefs and accepted a belief in a new religion or were less active in any organized religion. Thus, the NDE may have a variety of consequences on the religion of a person, from conversion or confirmation of faith, all the way to a renunciation of and a departure from mainstream religion. There is only proof that NDEs lead to increased importance of religion and to a growth in religious activity when the subject group is evaluated as a whole (McLaughlin and Malony 1984).

As demonstrated through NDEs, mystical experiences are often seen to comprise good values, attitudes, views, beliefs, and emotions, and they are regarded as human experiences that are, at least theoretically, attainable to everyone (Greyson 2014). They are generally defined by a conscious knowledge of ultimate truth or divinity, as well as an experienced unity with it, albeit this experience may not be present in every spiritual school. Mystical experiences, according to William James, are distinguished primarily by their noetic nature and ineffability, as well as the fact that they are frequently fleeting and passive experiences. People who describe mystical experiences show indicators of better adjustment than comparison groups, and mystical experiences can even help people who are depressed (Greyson 2014). Pahnke, using the work of James and Stace, developed a model incorporating nine common mystical consciousness characteristics: unity, transcendence of time and space, deeply felt positive mood, sense of sacredness, noetic quality, paradoxicality, alleged ineffability, transiency, and persistent positive changes in attitudes and behaviors (Pahnke 1969; Pahnke and Richards 1970). In contrast, people's altered states of consciousness generally move through three stages as they approach death, according to Noyes: resistance to dying, submission and life review, and eventually transcendence (Noyes and Kletti 1972; Noyes and Slymen 1979). Ineffability, transcendence of time and space, feeling of truth, loss of control, increased emotion, and distorted perception are all characteristics of mystical experience in this last phase (Greyson 2014). He later defined the mystical component as a sensation of tremendous insight, harmony or oneness, joy, revelation, heightened visual imagery, life review, and a sense of being directed by an outside force in response to acute life-threatening peril (Greyson 2014).

Some authors have seen parallels between near-death experiences and other mystical encounters. Cressy compared NDE phenomenology and aftereffects to the lifelong mystical experiences of medieval Roman Catholic mystics St. Teresa of Avila and St. John of the Cross, highlighting the similarities between ecstatic out-of-body travel, visions of God, clairvoyance, loss of fear of death, and healing transformations (Greyson 2014). Near-death experiences, according to Badham, have many of the features of deep mystical experience, and contemporary resuscitation procedures have made profound noetic experiences available to ordinary people, which were previously only attainable on rare occasions (Badham 1997). Pennachio discovered evidence of all nine elements of mystical experience described by Stace in NDE accounts (Greyson 2014; Pennachio 1986). According to Wulff, NDEs differ from traditional mystical experiences in their emphasis on individual identity, such as life reviews and interactions with departed relatives, the relative clarity of events, and the lesser frequency of a sense of unity (Greyson 2014). Hufford stated that the lower prevalence of 
oceanic sensations in NDEs does not rule them out as authentic mystical experiences, and that NDEs typically meet the criterion of mystical experience (Greyson 2014). NDE and mystical experience, according to Marshall, are not mutually exclusive concepts due to their phenomenological overlap, since the former is defined by its conditions and the latter by its contents (Greyson 2014; Marshall 2005). These debates in the literature point to the necessity for a scientific examination of mystical components in NDEs.

As Bruce Greyson argues, the phenomenological parallels between near-death and mystical experiences imply that the allegedly comparable transforming nature of these events warrants additional exploration (Greyson 2014). NDEs are said to have a profound and long-lasting effect, causing people to lose their fear of death, strengthen their belief in postmortem survival, strengthen their relationship with the divine, gain a new sense of meaning and purpose, increase their self-esteem, increase their compassion and appreciation for nature, and have less interest in material gain or social status (Greyson 2014). For more than a century, mystic experiences have been recognized as causing sudden and lasting changes in character and values, including changes in a person's relationship with God, perception and appreciation of nature, attitude toward the self, and attitude toward others (Greyson 2014).

\section{New Frontiers on NDEs and Spirituality}

In reality, there has been a frenzy of work in the field of near-death study since the publication of Raymond Moody's Life After Life in 1975. Both believers and skeptics have raced to the forefront, trying to shed light on the mysterious phenomenon of NDE. Neardeath experiencers' accounts frequently strain the boundaries of veracity, yet their allure is obvious. The possibility of NDEs providing indisputable proof of life beyond death further adds to their attraction. In other words, is an NDE a genuine visit to the hereafter, or are they simply the hallucinations of a dying brain? This basic issue is at the heart of much NDE study, and it is the answer to it that gives this incredible experience its enormous power. The explosion of interest in near-death studies over the last several decades has resulted in a plethora of hypotheses attempting to address this topic. Models based on psychological, cultural, physiological, and spiritual aspects, as well as hybrids, have all been offered. Currently, biological and spiritual theories are by far the most common.

However, the relevance of my question rests in the models' consequences for humanity and human existence, not in the models themselves (Newberg 2010). Biological hypotheses, for example, claim that NDEs are the outcome of a dying brain's activities. According to these and other researchers, the occipital cortex, frontal lobes, hippocampus, basal ganglia, amygdala, and, in many cases, the temporal/parietal junction are all implicated in NDEs. When the brain's oxygen supply is reduced, it might react in ways that lead to a patient's NDE. Other circumstances, such as general anesthesia and medications such as ketamine, LSD, and cannabis, can cause pleasure, visual hallucinations, tunnel vision, and transcendental sensations (Ammermann et al. 2007; Blanke and Dieguez 2009; French 2005). Patients with aberrant temporal lobe EEG patterns may experience an intensification of emotions as well as a sense of personal destiny. Patients who have their temporal lobes activated also describe memory flashbacks, life-in-review, and mystical experiences. The right posterior temporal lobe and the temporal/parietal area are the most common sites for out-of-body experiences. As a result, it appears that NDEs share characteristics with other scenarios and can be triggered by pharmaceutical drugs, epileptic discharges, or direct brain stimulation (Blanke and Thut 2007; Waxman 1975). Spiritual models stand in opposition to biological answers. These models frequently accept the NDE at face value, presuming that the bizarre interactions recorded by those who experienced an NDE occurred. One such concept, offered by Ring, asserts that out-of-body experiences by persons on the verge of death indicate a true separation of spirit, soul, and mind from the body. As a result, these models usually accept a continuous human existence after death and look for proof of human survival in NDEs (Newberg 2010). 
Given the limitations of both models, Andrew Newberg and Eugene d'Aquili introduced a theoretical neurophysiological model of the NDE based on our current scientific understanding of brain experiences during NDE (Newberg and d'Aquili 1994). Specifically, their model reconsiders some aspects of the Jungian archetypal hypothesis and how the neural activation of certain archetypes may be involved in the NDE. In addition, Newberg and d'Aquili proposed more specific neural pathways that might be responsible for such archetypal activation, thus generating the NDE (Newberg and d'Aquili 1994). Newberg and $\mathrm{d}$ 'Aquili argue that the activation (or partial activation) of two archetypes-the archetype of Dissolution and the archetype of Transcendent Integration-is believed to be the cause of NDE. Assuming that these archetypes are basic components of neuropsychological structures, Newberg and d'Aquili suggest that the various brain areas in the activation of these archetypes make sense in the context of NDE (Newberg and d'Aquili 1994).

The NDE accounts examined over the last few decades appear to imply that NDE is largely good (Newberg and d'Aquili 1994). The situation, on the other hand, is not straightforward. There are a growing number of examples in which the NDE appears to be a dreadful and frequently terrifying experience. These terrifying NDEs appear to be downplayed and occasionally not reported in line with our culture's optimism in these things. Furthermore, NDE experiences also appear to be influenced by an individual's cultural and religious background (Newberg and d'Aquili 1994). To incorporate these observations, Newberg and d'Aquili proposed an archetypal model. In this model, Newberg and d'Aquili argue that NDEs trigger two archetypes sequentially throughout the whole NDE.

The first is what Newberg and d'Aquili call the Dissolution archetype, which is made up of pictures of torture, slicing apart, burning, and other gruesome situations that represent the impending death, fragmentation, and destruction of the corporeal self. This is followed by the activation of what Newberg and d'Aquili call the Transcendent Integration archetype. It is this motif that brings the traditional otherworld travels to a close in both the East and the West, as well as practically all current NDEs (Newberg and d'Aquili 1994). With regard to the positive versus negative difference in NDE reports, Newberg and d'Aquili emphasize the cultural influence on the tenor of NDEs, claiming that it is likely that our society's general optimistic hopes for a possible otherworld, combined with the general elimination of any vivid sense of personal sin and guilt of a transcendent nature, will abort the full constellation of the archetype of Dissolution in contemporary NDEs. As a result, the modern experiencer of an otherworld excursion may proceed fast from a short and hazy discomfort, or at most, to totally transcending archetypal integration (Newberg and d'Aquili 1994). By examining classic NDE accounts from both the East and the West, as well as the more often reported frightening modern NDEs, it is clear that there are two distinct constellations of components, both of which are very comparable across cultures.

Mechanistically, Newberg and d'Aquili believe that ergotropic activation of the amygdala triggers an interaction with the neocortex of the inferior temporal lobe, resulting in hyperlucid images with scary contents. According to Newberg and d'Aquili, the ergotropic drive elicited by stress in the early phases of real physical disintegration has a feature that is particular for activating fear centers in the amygdala and, ultimately, the archetype of Dissolution. Then, as the ergotropic system reaches its maximum stimulation, a trophotropic breakthrough occurs. Newberg and d'Aquili argue that this very uncommon condition of second-stage autonomic tuning activates the OBE as well as deeply quiet and calm sentiments, especially when the chain of events is triggered by extreme physiological discomfort. The fact that most current near-death experiencers first have emotions of calm shows that trophotropic stimulation is important for the formation of happy NDEs, especially those that follow the awful features of the archetype of Dissolution. Furthermore, the fact that most ND experiencers maintain these calm sentiments throughout the good NDE suggests that trophotropic drive is likely to be responsible for the NDE beyond the ergotropic period. The experiencer finally awakens the archetype of Transcendent Integration as the trophotropic stimulation persists. 
Taken together, Newberg and d'Aquili argue that our understanding of consciousness and, ultimately, NDEs should include the following four properties (Newberg and d'Aquili 1994):

1. A strong sense of the reality of what is experienced.

2. Endurance of that reality through very long periods of time, usually only interrupted by the sleep state.

3. The sense that when elements in it undergo formal dissolution they have in fact ceased to be.

4. High cross-subjective validation for the details of perception, but somewhat less cross-subjective validation for the core meaning of perceptions.

The NDE is one of the most unusual examples of a spontaneous spiritual experience. As previously stated, NDEs have been widely recorded and examined, with multiple scientific publications devoted to the subject. Phenomenological analysis and certain approaches to the neuropsychological correlates of these experiences have also been examined (Newberg et al. 2002; Newberg 2010). Knowledge about these experiences, on the other hand, has the potential to bring crucial insights into the research and analysis of spiritual experiences. NDEs have been experienced, written about, and debated since the Tibetan Book of the Dead, the Middle Ages, and up to the current day. There is no denying that many people believe they have experienced near-death experiences. However, the exact mechanism through which and why the NDE occurs is still unknown. In reality, there has been a great deal of debate about the true nature and genesis of NDEs (Newberg et al. 2002).

Whether these near-death experiences represent perceptions of what is outside our usual sensorium and concept of consciousness is a scientifically problematic question (Konopka 2015; Newberg 2010). To comprehend the prevalence of near-death experiences in patients who appear to lack a functional brain, we may need to abandon our present physiological paradigms and consider other explanations for the occurrence. Near-death experiences may provide a glimpse into the notion of a universal mind that exists beyond time and space (Konopka 2015; Newberg 2010). The validity, significance, relevance, and need for study into the neurology of religious and spiritual practices and experiences (e.g., NDEs) has expanded, raising fundamental questions about the validity, importance, relevance, and need for such research (Newberg 2010, 2014). While the neuroscientific study of religious and spiritual experiences has progressed significantly since some of the early studies over 30 years ago, this field of inquiry is still in its infancy. In addition to the normal financing and academic status constraints, this discipline faces a number of distinct methodological problems. Pursuing such undertakings, on the other hand, may pay off handsomely for both science and spiritual disciplines. Such research may aid in a better understanding of the human experience of spirituality and religion from a religious standpoint. From a scientific standpoint, such study may aid in the understanding of the human brain's intricate workings, as well as the general link between brain states and body physiology (Newberg 2010, 2014).

\section{Conclusions}

Near-death experiences expose the deep-seated spirituality inherent in human beings. This becomes more apparent for patients near the end of the life. Near-death experiences show how these experiences help patients to discontinue anxiously attempting to exert control over their external conditions. Rather, people develop attitudes and perspectives on death and dying that make such control less necessary. Rather than attempting to control everything, faith enables individuals to let go of their need for control and believe that God will take care of their problems based on God's love, wisdom, and unique understanding of their circumstances (Greyson and Khanna 2014; Khanna and Greyson 2014a, 2015; Koenig 2002). These people are not looking for a place to call home on this planet. Instead, they are looking forward to coming home, to their true home, where they will be reunited with loved ones who have already passed away, as well as loved ones who are still alive. Dying is primarily about bidding a final farewell to loved ones and providing solace in their grief. It is a journey back to a place where they will no longer be in agony or suffering, 
but instead will have new bodies that will never become ill again. Death, for those who have experienced NDEs, is a period of profound healing and completeness, unlike any other (Greyson and Khanna 2014; Khanna and Greyson 2014a, 2015; Koenig 2002). Most individuals have little influence over the details of their death, such as when they die, where they die, how they die, how others treat them while they die, and so on. They have no way of knowing if they will die in "a refuge suffused with one's own order".

As NDEs show, it is much more necessary for us, the living, to provide a loving and caring atmosphere for the dying. It is critical that others' suffering elicits compassion and a desire to address the physical, emotional, and spiritual needs of persons who are dying. Patients and their family need to have all of their medical, psychological, social, and spiritual needs met during their final days of life. In clinical treatment or scientific research, none of these topics should be overlooked. When they are handled in a compassionate, sensitive, and patient-centered manner, the patient, family, and health-care professionals are more likely to find the dying process to be both comfortable and meaningful. Patients need spiritual materials made available to them in a nonthreatening manner and at their own speed. Finding purpose and meaning, forgiving and accepting forgiveness, sustaining hope, saying goodbye, and coming to grips with whatever they believe will happen when they die are all spiritual demands of patients who are not religious. In this respect, NDEs are a reminder to healthcare professionals that addressing the spiritual needs of the patients remains an integral component of end-of-life care.

As NDEs demonstrate, religion, medicine, and healthcare have been linked in some form in all human groups (Koenig 2012; Pargament 2011; Rosmarin and Koenig 2020). Despite the unfavorable views and attitudes of many mental health experts, research on religion, spirituality, and health is quickly expanding — and the majority of it is taking place outside of the realm of psychiatry (Koenig 2012; Pargament 2011; Rosmarin and Koenig 2020). Both medical and psychiatric patients utilize religious and spiritual beliefs and practices to deal with disease and other stressful life events. People who are more religious and spiritual have better mental health and adjust to health difficulties more rapidly than those who are less religious and spiritual, according to a substantial body of research (Pargament 2011; Rosmarin and Koenig 2020). These potential mental health and wellbeing advantages have physiological ramifications that influence physical health, illness risk, and treatment response. In general, these studies show a strong relationship between religious experience and health outcomes (Koenig 2012; Pargament 2011; Rosmarin and Koenig 2020).

There seems to be a complicated connection between religion and NDEs. At a particular level, though, the NDEs have shown a wide range of outcomes, from spectacular conversion to disillusionment with organized religion without impact. However, these experiences touch upon the common religious experiences of human beings regardless of any previous religious or philosophical leaning. In general, viewing NDEs from a point of view informed by both science and religion may constitute a paradigm change in medical treatment combining scientific research and belief with patient disease experiences with a new understanding of spiritual and medical relationships. Since the Enlightenment, reductionism has been an important component of the development of science and Western civilization. The practice of abstracting and reducing parts of the universe to their essential components has greatly enhanced the knowledge of the physical and chemical laws in all realities. However, the medical paradigm of the 20th century underlined the human being's holistic character. In this regard, the human person is seen not as a mechanical process defined exclusively by physical rules but as an interconnected totality. With the new medical paradigm, the complex social and environmental connections that influence human health and illness were more understood. New facts or interpretations can, just like with any perspective of philosophy or science, challenge or expand the current ideas, yet old paradigms are inflexible to take these changes. As David Brooks wrote,

"This new wave of research will not seep into the public realm in the form of militant atheism. Instead, it will lead to what you might call neural Buddhism .... . 
In unexpected ways, science and mysticism are joining hands and reinforcing each other.... We're in the middle of a scientific revolution. It's going to have big cultural effects". (Kopel and Habermas 2019)

Author Contributions: Authors contributed equally in this research. All authors have read and agreed to the published version of the manuscript.

Funding: This research received no external funding.

Conflicts of Interest: The authors declare no conflict of interest.

\section{References}

Ammermann, Heidi, Jan Kassubek, Martin Lotze, Ernst Gut, Michael Kaps, Joachim Schmidt, Frank A. Rodden, and Wolfgang Grodd. 2007. MRI brain lesion patterns in patients in anoxia-induced vegetative state. Journal of the Neurological Sciences 260: 65-70. [CrossRef]

Badham, Paul. 1997. Religious and near-death experience in relation to belief in a future life. Mortality 2: 7-21. [CrossRef]

Belanti, John, Mahendra Perera, and Karuppiah Jagadheesan. 2008. Phenomenology of near-death experiences: A cross-cultural perspective. Transcult Psychiatry 45: 121-33. [CrossRef]

Blanke, Olaf, and Gregor Thut. 2007. Inducing out-of-body experiences. In Tall Tales about the Mind and BrainSeparating Fact from Fiction. Oxford: Oxford University Press, pp. 425-39.

Blanke, Olaf, and Sebastian Dieguez. 2009. Leaving Body and Life Behind: Out-of-Body and Near-Death Experience. In The Neurology of Consciousness, 2nd ed. Edited by Steven Laureys, Olivia Gosseries and Giulio Tononi. Amsterdam: Elsevier, pp. $303-25$.

Cant, Robyn, Simon Cooper, Catherine Chung, and Margaret O'Connor. 2012. The divided self: Near death experiences of resuscitated patients-A review of literature. International Emergency Nursing 20: 88-93. [CrossRef]

Egmond, Daniel Van. 1993. Body, Subject and Self: The Possibilities of Survival after Death. Utrecht: Utrecht University Press.

Facco, Enrico, Christian Agrillo, and Bruce Greyson. 2015. Epistemological implications of near-death experiences and other nonordinary mental expressions: Moving beyond the concept of altered state of consciousness. Medical Hypotheses 85: 85-93. [CrossRef]

Fischer, John Martin, and Benjamin Mitchell-Yellin. 2014. Immortality and Boredom. The Journal of Ethics 18: 353-72. [CrossRef]

French, Christopher C. 2005. Near-death experiences in cardiac arrest survivors. In Progress in Brain Research. Amsterdam: Elsevier, pp. 351-67.

Greyson, Bruce. 1983. The Near-Death Experience Scale. The Journal of Nervous and Mental Disease 171: 369-75. [CrossRef]

Greyson, Bruce. 1998. The Incidence of Near Death Experiences. Medicine and Psyciatry 1: 92-99.

Greyson, Bruce. 2010. Implications of near-death experiences for a postmaterialist psychology. Psychology of Religion and Spirituality 2: 37-45. [CrossRef]

Greyson, Bruce. 2014. Congruence Between Near-Death and Mystical Experience. The International Journal for the Psychology of Religion 24: 298-310. [CrossRef]

Greyson, Bruce. 2015. Western Scientific Approaches to Near-Death Experiences. Humanities 4: 775-96. [CrossRef]

Greyson, Bruce, and Surbhi Khanna. 2014. Spiritual transformation after near-death experiences. Spirituality in Clinical Practice 1: 43-55. [CrossRef]

James, William. 1902. The Varieties Of Religious Experience: A Study In Human Nature. London: Penguin Classics.

Khanna, Surbhi, and Bruce Greyson. 2014a. Near-death experiences and spiritual well-being. Journal of Religion and Health 53: 1605-15. [CrossRef]

Khanna, Surbhi, and Bruce Greyson. 2014b. Daily spiritual experiences before and after near-death experiences. Psychology of Religion and Spirituality 6: 302-9. [CrossRef]

Khanna, Surbhi, and Bruce Greyson. 2015. Near-Death Experiences and Posttraumatic Growth. The Journal of Nervous and Mental Disease 203: 749-55. [CrossRef]

Koenig, Harold G. 2002. A commentary: The role of religion and spirituality at the end of life. The Gerontologist 42: 20-23. [CrossRef]

Koenig, Harold G. 2012. Religion, spirituality, and health: The research and clinical implications. ISRN Psychiatry 2012: 278730. [CrossRef]

Konopka, Lukasz M. 2015. Near death experience: Neuroscience perspective. Croatian Medical Journal 56: 392-93. [CrossRef]

Kopel, Jonathan, and Gary R. Habermas. 2019. Neural Buddhism and Christian mindfulness in medicine. Proceedings (Baylor University. Medical Center) 32: 308-10. [CrossRef]

Marshall, Paul. 2005. Mystical Encounters with the Natural World: Experiences and Explanations. New York: Oxford University Press.

McLaughlin, Steven A., and H. Newton Malony. 1984. Near-death experiences and religion: A further investigation. Journal of Religion $\mathcal{E}$ Health 23: 149-59. [CrossRef]

Newberg, Andrew, Eugene D'Aquili, and Vince Rause. 2002. Why God Won't Go Away: Brain Science and the Biology of Belief. New York: Ballantine Books.

Newberg, Andrew. 2010. Principles of Neurotheology. Oxfordshire: Routledge. 
Newberg, Andrew. 2014. The neuroscientific study of spiritual practices. Frontiers in Psychology 5: 215. [CrossRef] [PubMed]

Newberg, Andrew B., and Eugene G. d'Aquili. 1994. The Near Death Experience as Archetype: A Model for "Prepared" Neurocognitive Processes. Anthropology of Consciousness 5: 1-15. [CrossRef]

Noyes, Russell, and Roy Kletti. 1972. The Experience of Dying from Falls. OMEGA-Journal of Death and Dying 3: 45-52. [CrossRef]

Noyes, Russell, and Donald J. Slymen. 1979. The Subjective Response to Life-Threatening Danger. OMEGA-Journal of Death and Dying 9: 313-21. [CrossRef]

Pahnke, Walter N. 1969. The Psychedelic Mystical Experience in the Human Encounter with Death. Harvard Theological Review 62: 1-21. [CrossRef]

Pahnke, Walter N., and William A. Richards. 1970. Implications of LSD and Experimental Mysticism. Journal of Psychedelic Drugs 3: 92-108. [CrossRef]

Pargament, Kenneth I. 2011. Spiritually Integrated Psychotherapy: Understanding and Addressing the Sacred. New York: The Guilford Press.

Pennachio, John. 1986. Near-death experience as mystical experience. Journal of Religion $\mathcal{E}$ Health 25: 64-72. [CrossRef]

Pew Research Center. 2009. Many Americans Mix Multiple Faiths. Available online: https://www.pewtrusts.org/en/research-andanalysis / reports / 2009/12/09/many-americans-mix-multiple-faiths (accessed on 21 July 2020).

Rosmarin, David, and Harold Koenig. 2020. Handbook of Spirituality, Religion, and Mental Health. Cambridge: Academic Press.

Rousseau, David. 2011. Near-death experiences and the mind-body relationship: A systems-theoretical perspective. Journal of Near-Death Studies 29: 399-435. [CrossRef]

Sartori, Penny, Paul Badham, and Peter Fenwick. 2006. A prospectively studied near-death experience with corroborated out-of-body perceptions and unexplained healing. Journal of Near-Death Studies 25: 69-84. [CrossRef]

Sleutjes, Adriana, Alexander Moreira-Almeida, and Bruce Greyson. 2014. Almost 40 Years Investigating Near-Death Experiences. The Journal of Nervous and Mental Disease 202: 833-36. [CrossRef]

van Lommel, Pim. 2006. Near-Death Experience, Consciousness, and the Brain: A New Concept about the Continuity of Our Consciousness Based on Recent Scientific Research on Near-Death Experience in Survivors of Cardiac Arrest. World Futures 62: 134-51. [CrossRef]

van Lommel, Pim. 2013. Non-local Consciousness: A Concept Based on Scientific Research on Near-Death Experiences During Cardiac Arrest. Journal of Consciousness Studies 20: 7-48.

van Lommel, Pim. 2014. Getting Comfortable With Near-Death Experiences: Dutch Prospective Research on Near-Death Experiences During Cardiac Arrest. Missouri Medicine 111: 126-31. [PubMed]

Waxman, Stephen G. 1975. The Interictal Behavior Syndrome of Temporal Lobe Epilepsy. Archives of General Psychiatry 32: 1580. [CrossRef] 